\title{
PTU-038 ASPIRIN, NSAIDS, CALCIUM-CHANNEL BLOCKERS AND STATINS IN THE AETIOLOGY OF PANCREATIC CANCER: PRELIMINARY RESULTS FROM A CASE- CONTROL STUDY IN TWO CENTRES IN THE UK
}

doi:10.1136/gut.2011.239301.166

T F G Pugh, ${ }^{1,2^{*}}$ M Little, ${ }^{1,2}$ F Carey, ${ }^{1,2}$ M Metcalfe, ${ }^{3}$ R Robinson, ${ }^{3}$ A Clark, ${ }^{1,2}$ R Ndokera, ${ }^{3}$ H Ing, ${ }^{3}$ A Dennison, ${ }^{3}$ A Hart 1,2 'School of Medicine, Health Policy \& Practice, University of East Anglia, Norwich, UK; ${ }^{2}$ Department of Gastroenterology Norfolk and Norwich University Hospital, NHS, Norwich, UK; ${ }^{3}$ Leicester General Hospital, University Hospitals of Leicester, NHS, Leicester, UK

Introduction There are plausible mechanisms that carcinogenesis may be altered by: aspirin, NSAIDs, calcium-channel blockers and statins, through both inhibition of cyclo-oxygenase enzymes and the production of mediators of the cell cycle. The current epidemiological data in this area is either limited, reports conflicting results or does not consider important confounders. The aim of this study was to investigate whether there is a negative association between these medications and the development of pancreatic cancer in a case-control study in the UK.

Methods Clinical management databases were used to identify patients diagnosed with pancreatic cancer managed in Norfolk (years 2004-2006) and Leicestershire (2007). The use of these medications, prior to diagnosis, was recorded from a detailed review of the medical records. The control group were 251 dermatology patients of similar ages treated for basal cell carcinoma. ORs with $95 \% \mathrm{CI}$, for the development of pancreatic cancer for each medication, were estimated using unconditional logistic regression and adjusted for gender, age at diagnosis, cigarette smoking and type II diabetes.

Results A total of 206 cases of adenocarcinoma of the pancreas (median age $=71$ years, range $49-99$ years, $52 \%$ women, a median survival of 3.5 months) and 251 controls were identified. Aspirin use was negatively associated with the development of pancreatic cancer ( $\mathrm{OR}=0.49,95 \%$ CI 0.29 to 0.84 , $\mathrm{p}=0.01)$. There were no associations with either NSAIDs ( $\mathrm{OR}=0.98$, CI 0.50 to $1.91, \mathrm{p}=0.95)$, statins ( $\mathrm{OR}=0.64$, CI 0.38 to $1.11, \mathrm{p}=0.11$ ) or calcium-channel blockers $(\mathrm{OR}=0.78,95 \% \mathrm{CI}$ 0.43 to $1.39, \mathrm{p}=0.40$ ).

Conclusion The data support a protective role for aspirin, but not currently for the remaining medications in the aetiology of pancreatic cancer. The work is continuing to identify more cases and controls that may confirm our preliminary results for aspirin's negative association and also show an effect for statins. Before aspirin can be recommended as a chemo-preventive agent, further population-based studies are required to confirm the association and provide detailed information on the dose of aspirin needed and its duration of use.

Competing interests None.

Keywords Adenocarcinoma of the pancreas, Aspirin, Calciumchannel blockers, NSAIDs, Pancreatic cancer, Statins. 